\title{
Intra- versus inter-annual variation in counts of reef fishes and interpretations of long-term monitoring studies
}

\author{
A. A. Thompson ${ }^{1, *}$, B. D. Mapstone ${ }^{2}$ \\ ${ }^{1}$ Australian Institute of Marine Sciences, PM Box No. 3, Townsville, Queensland 4810, Australia \\ ${ }^{2}$ CRC: Reef Research Centre, James Cook University, Townsville, Queensland 4811, Australia
}

\begin{abstract}
Many sampling strategies have been proposed as appropriate for describing spatial patterns in marine organisms. There remain, however, many problems with the description, analysis and interpretation of temporal variation in abundances of organisms. In particular, there is a need to understand temporal error in the estimation of abundance of mobile organisms. In this paper we report estimates of temporal variation in abundances of tropical reef fishes attributable to sampling error at diurnal, daily and 'monthly' scales and compare these to inter-annual variation that might arise from processes such as mortality and recruitment. Uncertainty in estimates taken from the same sites over consecutive days was large for several species and accounted for the majority of error in estimates of abundance within years. Sources of error in estimates of abundance are discussed with consideration of the implications for long-term sampling and monitoring of fish assemblages. Shortterm temporal variation must be considered along with spatial variation in the design and interpretation of temporal studies of mobile species.
\end{abstract}

KEY WORDS: Reef fish · Visual census · Temporal error

\section{INTRODUCTION}

Variation is ubiquitous in estimates of abundances of marine organisms. In sampling theory and methodology, much attention has focused on either accounting for or minimising 'unexplained' sampling variation, or 'noise', in estimates, in the interests of identifying systematic patterns to which can be ascribed models of determinism, or 'signal' (Green 1979, Andrew \& Mapstone 1987, Winer et al. 1992, Underwood 1993, 1997). In studies of tropical reef fishes, research often has focused on sources of spatial variation in abundance estimates (Sale \& Douglas 1981, Sale \& Sharp 1983, Fowler 1987, McCormick \& Choat 1987, Buckley \& Hueckel 1989). A perception seems to have arisen that abundances are likely to be influenced less by temporal heterogeneity than by spatial patchiness. Whilst this

*E-mail: a.thompson@aims.gov.au might be reasonable over short time scales for sessile organisms, patchiness and sampling variation in abundances of fast-moving, highly mobile organisms such as many reef fishes will arise from a variety of both spatial and temporal factors (Sale \& Douglas 1984, Lewis 1997, Ault \& Johnson 1998).

As with variation in space, variation in estimates of population density through time can arise from 3 general sources: (1) real changes in abundance, because of recruitment to or loss from populations; (2) temporary (=local) shifts in distributions of individuals, without net change in population size; and (3) sampling error. For reef fishes, temporary changes in local distributions typically will result from sampling at scales less than the home range of the fish being counted. Such effects will be exacerbated where short-term shifts in the area of habitat occupied occur because of factors such as foraging behaviour (Ogden \& Buckman 1972, Gladfelter 1979, Zeller 1997) and responses to tidal (Bray 1981), diurnal (Helfman 1986, Galzin 1987), and 
seasonal or spawning cycles (Samoilys \& Squire 1994, Samoilys 1997, Zeller 1998). Sampling error might arise also because fishes move across the boundaries of sampling units during the time taken to survey the units, even though they do not move away from the sampling site, or react positively or negatively to the presence of an observer (Fowler 1987, Kulbicki 1998). Such 'nuisance' variation in time will be especially important in studies of the temporal dynamics of populations.

Many studies of the dynamics of coral reef fish populations or assemblages have been concentrated on isolated patch reefs, based on the premise that patch reefs are effectively isolates, and unlikely to be subject to variation because of movement or migration of fishes (Smith \& Tyler 1975, Gladfelter \& Gladfelter 1978, Brock et al. 1979, Ogden \& Ebersole 1981, Sale \& Steel 1989). This assertion was questioned by Bohnsack (1983) and then disputed by Lewis (1997) and Ault \& Johnson (1998), who ascribed variation in the abundance of certain species to significant migration among patch reefs. It is now clear that the potential variation arising simply from sampling error or shortterm movement of fishes must be considered prior to ascribing pattern or causality to either spatial or temporal changes in abundance. The logistic constraints imposed by extensive spatial sampling in many situations (e.g. large-scale monitoring programs; Hodgson 1999) result in sampling most places only once per year. Similarly, in impact monitoring studies, sites often are sampled only once before or after an impact or annually over longer periods. In the context of longterm monitoring or impact assessment of reef fish populations, inadequate attention to sources of short-term temporal 'noise' may result in erroneous inferences about temporal stability or change in populations over longer periods (Underwood 1991, Stewart-Oaten et al. 1996). In this work we have investigated various levels of intra-annual variation in abundance estimates of reef fishes and considered these relative to the magnitudes of inter-annual variation that would be seen in a series of annual surveys. Our emphasis is on estimating the variation within annual samples in order to properly distinguish real change from sampling error.

\section{MATERIALS AND METHODS}

Field methods and sampling design. The Australian Institute of Marine Science (AIMS) conducts a longterm monitoring program (LTMP) involving annual surveys of a range of biota on 49 reefs over the length of the Great Barrier Reef (GBR), Australia (available at www.aims.gov.au/pages/research/reef-monitoring/ reefmonitoring-index.html). The program is primarily concerned with describing inter-annual and decadal patterns in abundances of reef fishes (and benthos) on the GBR. On each reef, abundances of reef fishes are sampled annually at 1 location. The location typically consists of continuous reef slope on the northern flank of the windward front reef zone. Within the location 3 sites, each comprised of five $50 \mathrm{~m}$ long transects are haphazardly selected and then permanently marked. Markers consist of steel pickets at the start and end of each transect with smaller steel guides at $10 \mathrm{~m}$ intervals. Where size of location allows, sites are separated by at least $250 \mathrm{~m}$. Transects are run roughly parallel to the reef crest in 6 to $9 \mathrm{~m}$ depth at each site with the distance between transects determined by the availability of suitable reef slope, being generally on the order of 10 to $20 \mathrm{~m}$.

Species level counts are taken along these transects using underwater visual survey methods based on that pioneered by Brock (1954). Transects of 2 widths are used for each survey. On the first pass of each transect, a $5 \mathrm{~m}$ wide belt centred on the marked transect is surveyed for all fishes in the families Scaridae, Siganidae and Zanclidae, selected species of the family Labridae, the genera Acanthurus, Ctenocheatus and selected Naso species (hereafter Acanthuridae), the genera Chaetodon, Chelmon, Forcipiger and Hemitaurichthys (hereafter Chaetodantidae), the genera Lethrinus and Monotaxis (hereafter Lethrinidae), the genera Lutjanus and Macolor (hereafter Lutjanidae), and fishes in the genus Plectropomus (Serranidae). On the return pass along each transect, all species of the family Pomacentridae, excepting those of the genus Abudefduf, are counted within a belt $1 \mathrm{~m}$ wide, with the marked line as the lower boundary. ${ }^{1}$ For this study the pomacentrid data were aggregated to genus level, giving separate analysis for the genera Acanthochromis, Amblyglyphidodon, Amphiprion, Chromis, Chrysiptera, Dascyllus, Neoglyphidodon, Neopomacentrus, Plectroglyphidodon, Pomacentrus and Stegastes. It is important to note that, while for the most part our taxonomic groupings are dominated by 1 or 2 common species at any particular reef, the use of grouped data in the following models may result in an underestimation of temporal variance because of opposite abundance changes between constituent species. The use of grouped data are, however, necessary for our estimates of variance taken from several reefs due to the patchy distribution of individual species at

\footnotetext{
${ }^{1}$ Transects were $10 \mathrm{~m}$ wide and $2 \mathrm{~m}$ wide for the initial surveys (1993). Changes in transect dimensions arose out of work by Mapstone \& Ayling (1998) and concern for the performance of the wider transects when visibility was poor. See Cheal \& Thompson (1997) for more detail
} 
the spatial scales sampled. We implicitly assume, therefore, that temporal sampling error will be similar within the taxonomic groupings used.

Although reefs (locations) are sampled once annually, for the present study subsets of reefs were sampled at various intra-annual scales to quantify temporal variation in counts. These intra-annual samples were repeated at 3 scales: within days (to estimate diurnal variation); on successive days (daily variation); and in different months separated by 1 to 9 mo (monthly variation).

Diurnal variation. Knowledge of systematic effects on counts within days enabled us to tailor-sample at those times of day when counts were expected to be most consistent, thus minimising the risk of confounding longer-term effects with time-of-day effects. Sampling was done throughout several days to identify potential diurnal variations in counts of reef fishes possibly related to features such as time of day and tidal cycle (Bray 1981, Helfman 1986, Galzin 1987).

Diurnal sampling was done at Davies Reef, off Townsville, over 3 consecutive days. Each of the 3 sites was sampled once during each of 6 time periods between 07:30 and 17:30 h. Sites were allocated to the forenoon (am) times and afternoon (pm) times over the $3 \mathrm{~d}$ in a latin square design (Table 1). A latin square allocation was used because it was not possible to sample all sites at all times on each day. Each of the 6 time periods was kept as short as possible by using 2 observers to sample each site. One observer surveyed 2 of the 5 transects at each site, while the other surveyed the remaining 3 transects, thus reducing by $40 \%$ the time taken to survey each site. The same observer surveyed the same transects for every repeat survey to avoid confounding temporal variation in counts with potential observer-specific bias (Thompson \& Mapstone 1997).

The diurnal data set was analysed initially using a repeated-measures analysis of variance (ANOVA) on the untransformed data. Straightforward split-plot models were used thereafter, since in all cases the necessary assumptions for a split-plot analysis were satisfied (Winer et al. 1992) and in no cases did Greenhouse-Geisser or Huyn-Feldt corrections alter the uncorrected results.

Two models were used to investigate possible timeof-day effects on abundance estimates. Both models were run using the general linear model (GLM) procedure (SAS Institute 1997), with the critical significance level set at 0.1 and $F$-ratio denominators set according to the Cornfield-Tukey algorithm (Underwood 1981, Winer et al. 1992). In both models, daily variation and the spatial factors site and transect (site) were treated as random, whilst period (am, pm) and time-of-day were considered fixed effects.
Table 1. Sampling design for estimates of diurnal variation in counts of fishes. Numbers in the table represent the site sampled during the hour beginning at the time (columns) and day (rows) indicated

\begin{tabular}{|ccccccc|}
\hline \multirow{2}{*}{ Day } & \multicolumn{7}{c|}{ Time of day (h) } \\
& $07: 30$ & $09: 00$ & $10: 30$ & $13: 30$ & $15: 00$ & $16: 30$ \\
\hline 1 & 1 & 2 & 3 & 1 & 2 & 3 \\
2 & 3 & 1 & 2 & 3 & 1 & 2 \\
3 & 2 & 3 & 1 & 2 & 3 & 1 \\
\hline
\end{tabular}

First we analysed the data with the following model:

Model 1

$y_{i j k l}=\mu+\psi_{i}+\phi_{j}+\delta_{k}+\psi \phi_{i j}+\psi \delta_{i k}+\phi \delta_{j k}+\psi \phi \delta_{i j k}+\varepsilon_{i j k l}$

where $\mu$ is the overall population mean, $\psi_{i}$ represents the random variations due to site, $\phi_{j}$ represents the effects of period of sampling (am or pm, with 3 samples of each transect in each), $\delta_{k}$ represents random daily variation, and $\varepsilon_{i j k l}$ is the (residual) variation attributable to transects within sites.

Note that in this model a test for the main effect of period was possible only if either period $\times$ site or period $x$ day (or both) effects were estimated to be approximately zero and could be eliminated from the model. Our primary interest in Model 1, however, was in the presence or absence of site $\times$ day effects which could potentially confound the time-of-day effects of most interest, which were investigated explicitly by the following model:

Model 2

$$
y_{i j k}=\mu+\psi_{i}+\tau_{j}+\psi \tau_{i j}+\varepsilon_{i j k}
$$

where $\psi_{i}$ is random variation due to site, $\tau_{j}$ is the effect of time-of-day, and $\varepsilon_{i j k}$ is the (residual) variation attributable to transects within sites.

Note that a significant site $\times$ period $\times$ day effect in Model 1 would be indistinguishable from a site $\times$ time effect in Model 2.

Presence of observer. The repeated presence of a diver on transects may have affected variation in counts or confounded inferences of diurnal patterns in counts by habituating the target fishes to the divers presence. Diver effects might have been either positive (attracting fishes to the transect) or negative (displacing fishes from the transect) (Fowler 1987, Kulbicki 1998). Such effects might have been manifest in 3 ways: (1) a one-off effect following the first count that resulted in all subsequent counts being either lower or higher than the first; (2) a cumulative effect that resulted in a monotonic change in counts with repeated visits; and (3) an effect on each day that resulted in the second count being consistently greater or less than the first count on each day. Accordingly, we analysed 
Table 2. Summary of numbers of reefs and surveys from which data were used to estimate variation at the various temporal scales. The exclusion of reefs on which a given taxon was very rare (average density $<1$ individual per transect) has meant that not all data from all surveys were used for every taxon

\begin{tabular}{lcc} 
Temporal period & No. of reefs surveyed & Total surveys \\
\hline Days & 3 & 28 \\
Months & 15 & 50 \\
Years & 48 & 236 \\
\hline
\end{tabular}

the time-of-day data to estimate whether there were trends in the data related only to the order in which counts were done. We fitted a repeated-measures model (Model 3) to the data and tested for significant linear or quadratic trends in the ordered data and for significant contrasts between the first count and average of all remaining counts on each day. If these ordered data failed tests for sphericity, we applied the Huyn-Feldt correction to degrees of freedom for all order effects (Winer et al. 1992).

Model 3

$$
y_{i j k}=\mu+\psi_{i}+\phi_{j}+\psi \phi_{i j}+\varepsilon_{i j k}
$$

where $\mu$ is the overall population mean, $\psi_{\mathrm{i}}$ is random variation due to site, $\phi_{j}$ is the effect of order of sampling (1st to 6th counts), and $\varepsilon_{i j k}$ is the (residual) variation attributable to transects within sites.

Daily, monthly and annual variation. Three locations were surveyed on 3 consecutive days on a total of 6 occasions (including the visit during which the diurnally stratified data were collected) and on 2 consecutive days on a total of 5 occasions. Data from these 11 visits were used to estimate daily variation in counts of the selected fishes. Data from which monthly variation was estimated were advantageously amassed from the AIMS LTMP database, and included samples ranging from 1 to 9 mo apart but always within the period bounded by annual recruitment peaks for the target reef fish (Sale 1991). Sites sampled on consecutive days were generally visited at similar times each day, and so variation due to systematic events such as diel migrations or tidal effects would be under-represented in those data. Accordingly, daily variation most probably expressed the effects of non-systematic movements of the fishes. Conversely, samples taken months apart were not taken at consistent times of day (or tidal cycle) and accordingly reflected variations in counts attributable to the compound effects of day, time of day (or tide) and influences such as seasonality or longerterm movements of fishes.

Samples separated by approximately 1 yr and which spanned known recruitment periods were used to estimate inter-annual variations in abundance. These data were taken from 48 reefs from a range of latitudinal and longitudinal positions on the GBR surveyed over the first 6 yr of the AIMS LTMP. Table 2 summarises the number of reefs from which data were used to estimate each scale of variation.

The temporal sources of variation days, months and years were all treated as random factors in a linear mixed model (SAS/STAT Software). The temporal factors were nested within each other in order of decreasing period and within the fixed spatial factor, reef. Both linear and quadratic regression terms were fitted to annual counts from each reef to account for variation due to potential trends in the data, prior to estimating the (non-trend) variation among years, months and days (Crowder \& Hand 1990, Winer et al. 1992). The removal of linear and quadratic trends from the annual samples prior to estimating temporal variation meant that our estimates of inter-annual variation described the compound effects of movement of fishes and stochastic variation, rather than systematic changes in abundance.

Site totals for each taxon were transformed $[\ln (x+1)]$ prior to analysis, and reefs for which abundance was lower than an average of 1 fish per transect were excluded to avoid the inflation of estimates of relative variation because of small changes in counts of rare taxa. To account for a change in transect dimension between the first 2 and later years of the project, surveys were coded as to whether they had been undertaken using 'wide' or 'narrow' transects. All pairs of data from which the intra-annual scales of variance (days and months) were estimated were collected using the same transect dimensions.

The resulting model fitted to the data was as follows:

$$
\begin{aligned}
& \text { Model } 4 \\
& \begin{aligned}
y_{i j k l}=\mu+\tau_{i}+\rho_{j} & +\beta_{1} \chi_{k(j)}+\beta_{2} \chi_{k(j)}^{2} \\
& +\lambda(\tau \rho)_{k(i j)}+v(\lambda(\tau \rho))_{l(i j k)}+\varepsilon_{m(i j k l)}
\end{aligned}
\end{aligned}
$$

where $\mu$ is a constant, $\tau_{i}$ is the effect of wide or narrow transects, $\rho_{j}$ is a fixed reef effect, $\beta_{1} \chi_{k(j)}$ and $\beta_{2} \chi^{2}{ }_{k(j)}$ are linear and quadratic terms for trends in abundance over years within reefs, $\lambda(\tau \rho)_{k(i j)}$ is the residual interannual variation within each reef and transect width after accounting for inter-annual trends, $v(\lambda(\tau \rho))_{l(i j k)}$ is the monthly variation within years, reefs and transect widths, and $\varepsilon_{m(i j k l)}$ is (residual) daily variation.

The object of the analysis was to estimate the variance of the difference between 2 reef means taken at different times, specifically:

- between 2 means taken within a few days of each other:

$$
\operatorname{Var}\left(\bar{y}_{i j k l 1}-\bar{y}_{i j k l 2}\right)=2 \sigma_{\varepsilon}^{2}
$$

- between 2 means taken within several months of each other: 


$$
\operatorname{Var}\left(\bar{y}_{i j k 1 .}-\bar{y}_{i j k 2 .}\right)=2 \sigma_{v}^{2}+2 \sigma_{\varepsilon}^{2}
$$

- between 2 means taken a year apart:

$$
\operatorname{Var}\left(\bar{y}_{i j 1 . .}-\bar{y}_{i j 2 . .}\right)=2\left(\sigma_{\lambda}^{2}+2 \sigma^{2}{ }_{v}+2 \sigma_{\varepsilon}^{2}\right)
$$

where $\sigma_{\varepsilon,}^{2},\left(\sigma_{v}^{2}+\sigma_{\varepsilon}^{2}\right)$ and $\left(\sigma_{\lambda}^{2}+\sigma^{2}{ }_{v}+\sigma^{2}{ }_{\varepsilon}\right)$ were the restricted maximum-likelihood estimates of daily, monthly and inter-annual variance resulting from application of Model 4 (SAS/STAT software: Changes and Enhancements through Release 8; SAS Institute). The variance components outlined above (Eqs. 4 to 6) were expressed as a proportion of the difference in mean abundance to relate temporal variability to observed changes in mean abundance sampled at various temporal scales. Standard deviations of the mean (untransformed) abundances were calculated as $\pm \mathrm{SD}=\exp \left( \pm \sqrt{2 \sigma^{2}}\right)$.

\section{RESULTS}

\section{Diurnal effects}

Potential confounding of the time-of-day effect in the form of significant day and/or day $\times$ site effects in Model 1 resulted for only the acanthurids and scarids. Both taxa also showed a significant site $\times$ period $\times$ day interaction ( $p<0.001, p=0.016$ respectively). Further examination of this result for the acanthurids showed that day effects were absent from all sites, but there was a significant interaction between day and period at Site 1. The interaction apparently stemmed from high estimates of Acanthurus nigrofuscus on the day that Site 1 was sampled in the earliest time period. This same point was also probably a main influence in the site $\times$ time-of-day interaction for the Acanthuridae when analysed by Model 2 ( $p=0.052)$, with little difference in abundance through time for Sites 2 or 3. For these fishes, then, we considered generalisations about time-of-day effects to be equivocal.

Although the Scaridae showed a significant day $\times$ site $(p=0.015)$ and site $\times$ day $\times$ period $(p=0.016)$ interaction (Model 1) and a significant site $\times$ time-of-day interaction (Model 2, p = 0.018), the plot in Fig. 1 shows a pattern with respect to time of day that was relatively consistent over the 3 sites. The main effect of time of day accounted for by far the largest proportion of sums of squares of all the effects in Model 2 for the Scaridae, indicating a strong effect of time of day. Low counts for Site 1 at Time 1 (on Day 1) were likely to have driven both the time $\times$ site interaction in Model 2 and the site $\times$ day $\times$ period interaction in Model 1 .

Of the remaining 15 taxonomic groups, 4 showed statistically significant site $\times$ time-of-day interactions $(\mathrm{p}<0.1)$ in Model 2 without confounding effects present in Model 1 (Fig. 1). Of these, the 2 invertebrate feeding groups Chaetodontidae and Labridae ( $p=0.070$ and $\mathrm{p}=0.051$ respectively) showed no consistent trends with respect to time of day (Fig. 1). Likewise, the heterogeneity of time-of-day effects among sites for Neopomacentrus azysron $(\mathrm{p}=0.008)$ and Pomacentrus spp. $(p=0.004)$ and their lack of systematic relation to time of day (Fig. 1) suggested that the effects we found were generally local phenomena. Hence, we concluded that no meaningful generalisations about sampling at different times of day could be made for these taxa.

A further 3 taxa showed significant (and unconfounded) time-of-day main effects (Fig. 1). The main effects of time of day evident for Chromis $(p=0.030)$ and Amphiprion ( $p=0.032$ ) were perhaps the strongest signals of predictable effects we saw, although the patterns for the 2 genera were opposite in direction (Fig. 1). Although a main effect of time of day was also significant for Plectroglyphidodon lacrymatus ( $p=0.068$ ), the counts were not monotonically related to the time of sampling, but rather showed a minimum during the middle of the day (Fig. 1).

\section{Influence of presence of observers}

Significant variation among counts related to the order in which they were done were found for several taxa. For Amblyglyphidodon, Chromis, Neopomacentrus, Pomacentrus, Acanthuridae, Chaetodontidae, Labridae, Lethrinidae and Serranidae these effects were inconsistent among sites and/or days, and in no cases were the patterns consistent with any of the 3 hypothesised manifestations of effects of observers on counts. Significant contrasts between the first counts and averages of all subsequent counts were found for Amphiprion (1st > rest) and Neoglyphidodon (1st < rest), indicating that the presence of divers may have had lasting effects following the first count. Consistent differences between the 1st and 2nd counts each day were found for Chrysiptera, Plectroglyphidodon and Scaridae, with the 1 st counts being greater than the 2nd counts on each day for each taxon. Thus, for these taxa we cannot exclude the possibility that fish were avoiding divers after their first encounters each day.

\section{Daily, monthly and annual variation}

Standard deviations of differences in abundance at sites surveyed repeatedly at the scales of days, months, and years are presented in Fig. 2. Note that since the temporal scales are nested within each other, the bars represent the cumulative variation in estimates of variance with increasing temporal period. While the overall variation at the various scales gives 

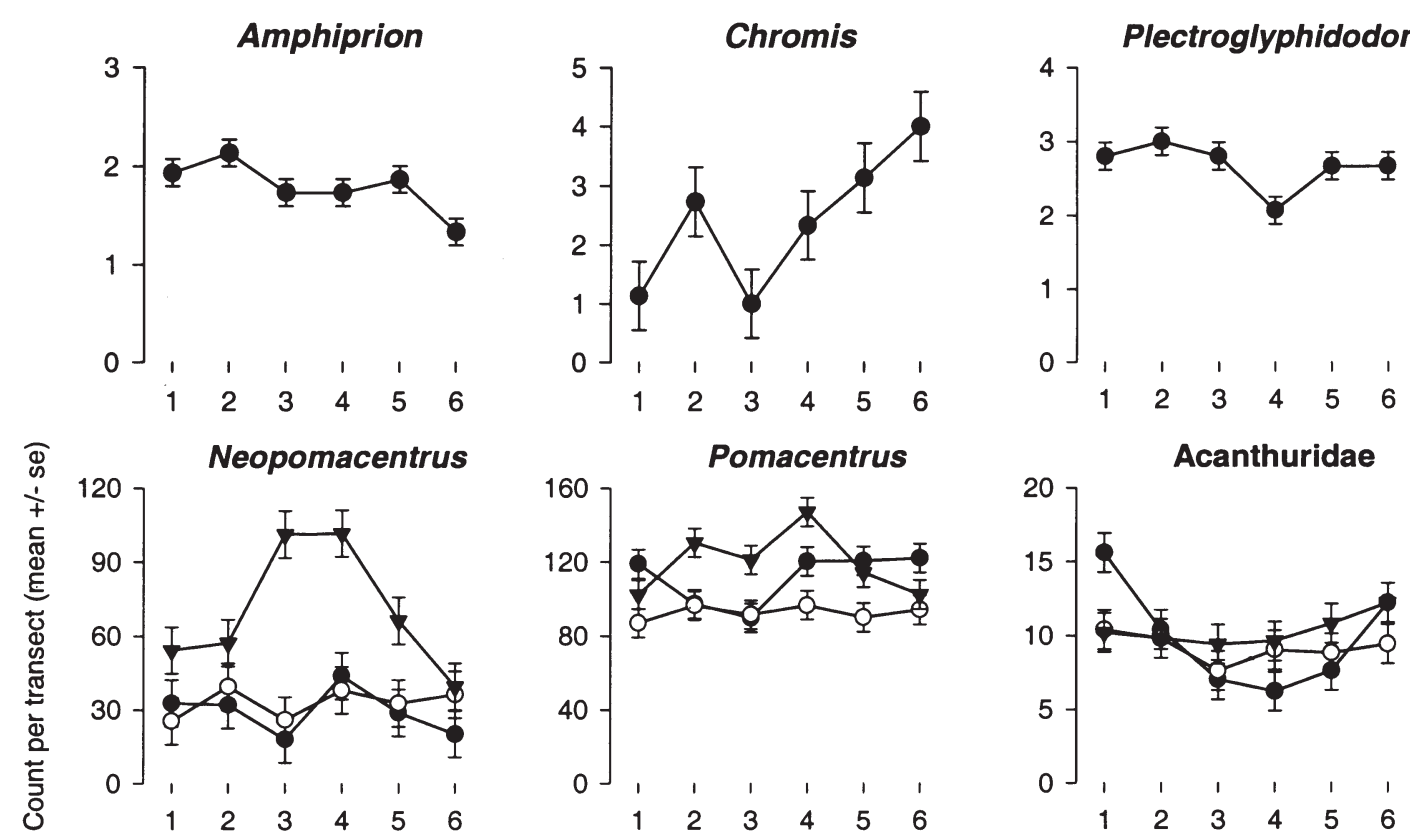

Pomacentrus

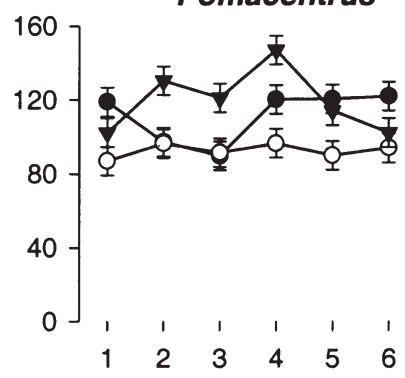

Acanthuridae
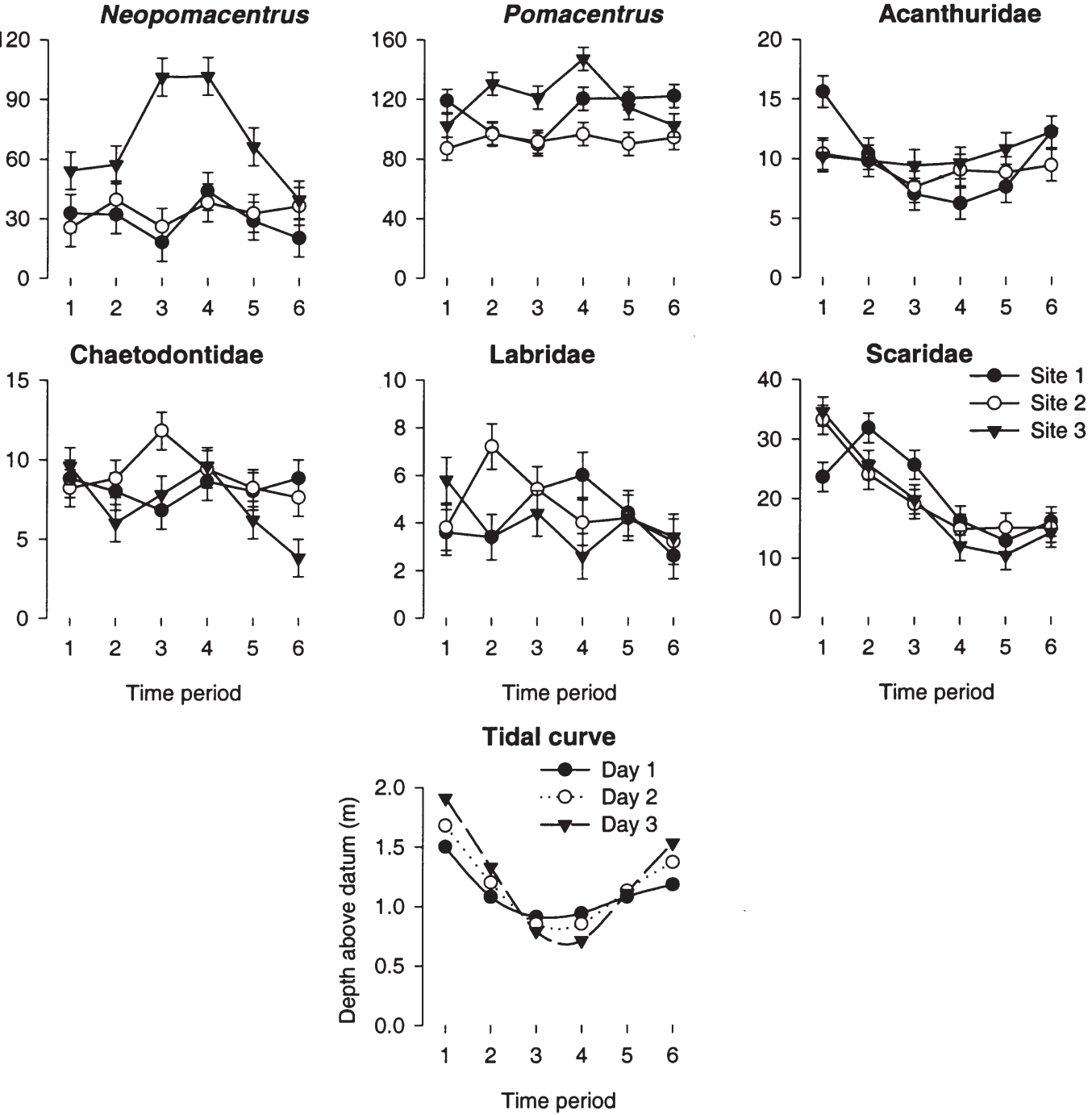

Fig. 1. Diurnal profiles in abundance for taxa that showed significant differences in abundance with time of day (see Table 1 for the 6 time periods) that were consistent across sites (top graphs) or varied among sites (graph rows 2 and 3). Also shown are plots of the tidal height for the 3 sampling days (bottom graph)

an indication of the likely power to detect change in the various taxa, the partitioning of variation between the 3 scales gives an indication of the relative importance of the processes affecting temporal distribution over different periods.
Daily variation accounted for an average of $69.6 \%$ of the overall intra-annual variation in repeated counts, with contributions ranging from around $27 \%$ for Neopomacentrus azysron and Pomacentrus spp. to $100 \%$ for the Lutjanidae, Siganidae, Serranidae, and 


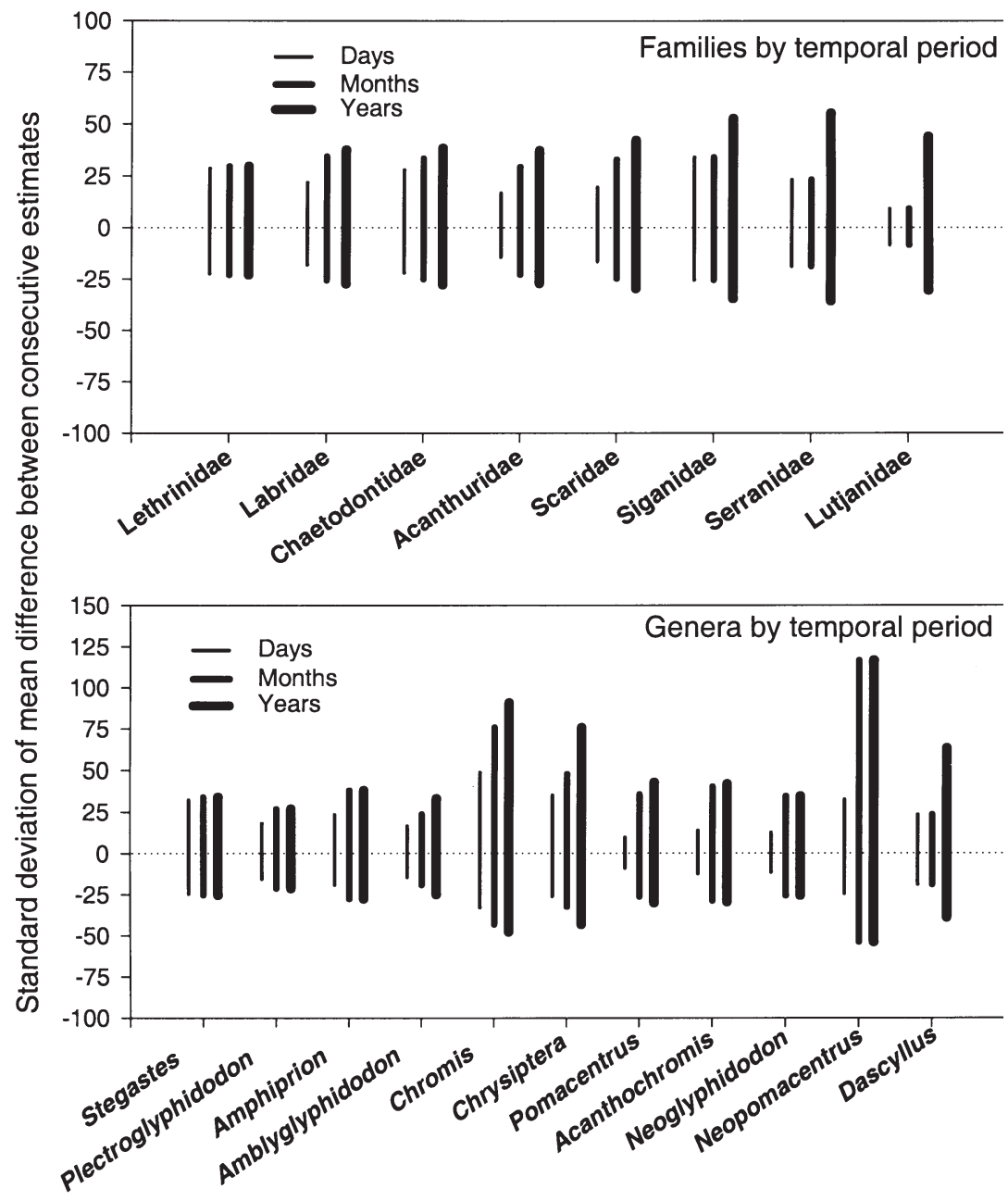

Fig. 2. Daily, monthly and inter-annual variation in reef means of counts of reef fishes. Bars represent 1 SD of the variation observed at each time scale. Approximately $65 \%$ of observed means will deviate from a previously observed mean within the limits demarcated by the bars for the given temporal scale simply because of inherent variations in counts

abundances of the Labridae, the Lethrinidae, Acanthochromis polyacanthus, Amphiprion spp., Neoglyphidodon spp., Neopomacentrus azysron, Plectroglyphidodon spp., and Stegastes spp. For the Acanthuridae, Chaetodontidae, Scaridae, Siganidae, Amblyglyphidodon spp., Chromis spp., Chrysiptera spp., and Pomacentrus spp., variances increased moderately from monthly to annual time scales, whilst for the remaining taxa there were relatively large increases in variance between these scales (Fig. 2). Together these patterns reveal that only 2 taxa showed little change in variance in counts over the 3 time scales considered (Stegastes spp. and Lethrinidae; Fig. 2).

\section{DISCUSSION}

We have presented estimates of variation in abundances of reef fishes at various temporal scales. Much of this variability is likely to stem from sampling related errors or short-term behavioural phenomena that do not reflect net changes in abundance at more than very local spatial or short temporal scales. These results have important implications for the design and conduct of long-term monitoring studies, but also for spatio-temporal comparisons of reef fish abundances generally.

Sampling design aimed at determin-

Dascyllus spp. Once linear and quadratic components of inter-annual variation had been accounted for, on average, only $21.2 \%$ of the overall variation was explained by longer-term, inter-annual processes, with estimates ranging from $0 \%$ (Lethrinidae, Amphiprion, Neoglyphidodon, Neopomacentrus, Plectroglyphidodon, and Stegastes) to $79.1 \%$ (lutjanids).

Several taxa showed negligible difference in variation between the scales of days and months. These included the Lethrinidae, Lutjanidae, Serranidae, Siganidae, Dascyllus spp, and Stegastes spp. For the remaining taxa there was marked additional variation between months over that attributable to daily changes (Fig. 2). Taxa fell into 3 main groups with respect to the relative magnitudes of monthly (intra-annual) and inter-annual variation. There were negligible increases in variance from monthly to inter-annual scales for ing temporal change frequently involves a choice between repeatedly sampling the same spatial units (e.g. transects or patch reefs) or sampling different spatial units on each sampling occasion. The rationale for repeated sampling is the removal of spatial variability from consecutive samples in order to improve the likelihood of detecting change. One reservation about repeated sampling is the effect of diver disturbance on subsequent estimates. It has been shown that the prior presence of a diver effects the number of butterflyfish observed along narrow transects at least in the short term (1 to $15 \mathrm{~min}$; Fowler 1987). It has also been suggested that behavioural response to divers varies for some species as a result of fishing pressure, which suggests some form of habituated response to human interactions (Kulbicki 1998). Analysis of our latin square design, in which transects had a minimum, 
of $5.5 \mathrm{~h}$ between samples and were sampled on 6 occasions, revealed no evidence of consistent responses either after the first survey or over the period of surveys for most taxa. For 3 taxa, the apparent effect of prior presence of divers was apparently lost or reset from one day to the next, whilst for 2 other taxa our data were consistent with effects persisting over $3 \mathrm{~d}$. Given these results, we suggest that for most of the taxa we sampled diver disturbance should be irrelevant in samples repeated at intervals of greater than a few days.

Time-of-day effects on abundances of reef fishes are obvious in terms of changes between nocturnal and diurnal assemblages of fishes during the crepuscular periods (Helfman 1986, Galzin 1987). Our focus was on describing any systematic variation within the diurnal assemblage that would need to be considered in the development of adequate temporal sampling designs. For the majority of grouped taxa investigated, the differences between the various sampling times seemed largely stochastic. While our data do not provide the basis for distinguishing whether any of the apparently systematic patterns observed were mainly driven by tidal state, time of day or, indeed, some other factor, tidal state is intuitively implicated in several of the patterns we see. One exception might the apparent declines in our estimates of abundances of Amphiprion spp. in late afternoon. Amphiprion spp. are extremely sedentary, rarely venturing from the immediate vicinity of their host anemone (Fautin \& Allen 1992). This habit suggests that their availability to the observer (sightability) is reduced in the late afternoon, possibly because of negative responses to the divers.

Tidal state may influence observed abundance in 2 main ways. Firstly, the effects of tides may create periodic feeding opportunities such as access to shallow areas of the reef during high tide (Klump \& Polunin 1990) or concentration of planktonic food resources as a response to water movements (Bray 1981). Secondly, the directions of movement of fishes have been shown to affect estimates of density of reef fishes in visual surveys (Watson et al. 1995). If it is assumed that fish will orientate, or indeed migrate, with respect to current flow, such directed movements could produce a sampling error associated with tidal state. It should be noted, however, that tidally-governed feeding opportunities may not necessarily influence observed abundance through the wholesale movement of fishes alone. Personal observations suggest that when not actively feeding, many fishes seek refuge within the coral matrix, and are thus less available to observation.

It is likely that the differences observed in the planktivorous pomacentrids (Chromis spp., Neopomacentrus azysron and Pomacentrus spp. [predominantly P. lepidogenys and $P$. moluccensis]) reflect a combination of behavioural (feeding vs sheltering), and fine-scale distributional changes as a result of the utilization of transient, tidally generated, feeding opportunities. Local movements also might explain the patterns seen in the abundance of Scaridae in this study. The diminishing numbers of Scaridae through the morning suggested that the fish were moving off the survey sites as tidal height decreased, possibly as a result of transiting the sites as they moved off the reef-crests and into deeper water as the tide fell (Polunin \& Klump 1988, Klump \& Polunin 1990). The presence of strong contrasts between pairs of counts on each day complicates the interpretation of this pattern, however. The strong pattern in counts of Scaridae related to time of day suggests that the observed differences between ordered pairs of counts within days was an artefact of the diurnal pattern. The presence of within-day effects alone would have precipitated a step-shaped plot of abundances from higher abundances in the morning (1st counts) to lower abundances in the afternoon (2nd counts). An alternative interpretation, however, is that the time of day effect arose from the overlay of a daily accumulating effect of divers on acute within-day effects. We consider the latter scenario an unlikely explanation of the observed patterns.

The highly site-attached nature of Plectroglyphidodon lacrymatus suggests that the low estimate of its abundance in the middle of the day is due to reduced sightability rather than a shift off the transects. It is possible that the high abundance of Scaridae in the morning may have induced heightened defensive behaviour by the territorial 'gardening' pomacentrid (pers. obs.), while the higher nutritional value of the algae in their territories in the afternoon has been shown to illicit increased feeding activity (Polunin \& Klumpp 1989). Both of these activities would increase the sightability of the fish to observers. The relatively low counts of $P$. lacrymatus in the early afternoon could be explained by the fish being less active and therefore less visible to observers.

For most of the grouped taxa we consider that potentially systematic effects due to time of day were either absent or trivial relative to smaller scale stochastic variations in abundance. Our results indicate that sampling during the middle of the day (between, for example, 2 to $3 \mathrm{~h}$ after sunrise and 2 to $3 \mathrm{~h}$ before sunset) will be a fairly secure strategy if visual surveys are to be structured to minimise possible time-of-day effects. This result is consistent with the previous work that indicates that time-of-day effects are generally most extreme about the crepuscular periods (Galzin 1987). Indeed, it is possible that the lack of time of day effects we saw in most taxa arose because our sampling began and ended at least $1 \mathrm{~h}$ distant from sunrise or sunset. 
Minimising effects of tidal state is more difficult, since in most cases tidal state is not consistently related to particular times of day. This presents a considerable problem when some taxa of interest respond to tidal state and logistic considerations preclude structuring surveys to coincide with particular tidal phases, as will usually be the case in large-scale, long-term monitoring programs. Perhaps the safest strategy to adopt in such cases is to ensure that sampling over the spatial scale of main interest (e.g. a location) is spread over an entire tidal cycle, so that confounding between tidal effects and spatial effects is avoided. Sampling replicates at different tidal states would effectively remove tidal influences from their mean and allow unconfounded comparisons among strata that were similarly sampled, although variation among replicate counts would be increased. If such a distribution of sampling effort is not possible, then, for some taxa it may be necessary to understand the generalised tidal effects sufficiently to model those effects and remove them from the count data before comparing strata sampled under different tidal conditions.

Even when sampled at similar times on consecutive days (to avoid the major likely sources of diurnal and/or tidal effects) we recorded considerable variation in counts among days. Assuming that tidal influences were minimised by our stratification, it seems likely that variable sightability and mobility of the fishes either across transect boundaries or over larger scales were responsible for this daily variation. Such uncertainty in counts should be factored into the interpretation of longer-term data relating to mobile organisms such as reef fishes. Such variations, if not properly accounted for, could have drastic influence on the conclusions from impact monitoring programs if incorrectly ascribed to perceived differences in conditions between sampling events (such as before versus after the commencement of a human activity). Our results indicate that it is not legitimate to assume that abundance estimates will be relatively constant over short periods. Replication of sampling within, before, and after strata (for example) is essential to avoid spurious inferences about the causes of perceived changes in abundances over even short periods (Underwood 1993, Stewart-Oaten et al. 1996).

The relationships between daily and monthly variations we documented fell into 2 broad categories: those showing little additional variation in samples taken among months and those showing considerable additional variation. This split was not clearly related to the sedentary or roving habits of the taxa, with both highly sedentary and more vagile taxa included in both groups. Notably, several of the taxa which displayed substantial changes in variation from daily to monthly scales would be expected to be relatively site-attached.
For example, the genera Chromis, Neopomacentrus, Acanthochromis and Pomacentrus, which are comprised of predominantly site- or at least area-attached species, showed marked discrepancy between daily and monthly variation. Given that the later counts were not consistently less than the earlier counts in these data, it seems unlikely that the monthly variation was attributable to substantial mortalities between samples. There are 3 possible but non-exclusive explanations for this observation.

First, variations in counts might be related to local shifts about the sampling area in response to transient feeding opportunities, as suggested in relation to within-day variability. Given the narrow band of the transects, schools shifting only a matter of metres vertically up or down the reef slope in response to local foraging opportunities may completely avoid the transect area during a particular tidal state. This phenomenon is readily observable on some reefs.

Second, an acknowledged problem with the sampling protocol from which these data came is centred on bias between observers in the classification of individuals to either Year 0 (not included in counts) or Year $1+$ age classes (Thompson \& Mapstone 1997). Amongday replicates were always collected by the same observer for each transect to obviate this. Amongmonth estimates, however, were in effect randomised across several observers, raising the prospect that observer biases in classification of fishes to age classes may have inflated monthly variation in counts. Further, intervals of several months between sampling occasions allowed for growth of individuals that might have confused the estimation of age $(0,1+)$ from observations of size.

Third, real changes in abundance may have occurred between samples, with net migration onto or off the sites as a result of some ontogenetic habitat shift.

Thus, estimates of monthly variation may have been exaggerated by inter-observer effects and changes in the proportion of the populations included in counts. We suggest, however, that such logistically constrained sources of error in surveys run over long periods are inevitable, although undesirable. Accordingly, any contributions to variation in counts they instigate should be identified and at best ameliorated through training of observers or procedural changes, or at least estimated before deriving inferences about real changes in populations among samples.

Once intra-annual variation (sampling error) had been taken into account, many of the taxa we considered showed trivial extra inter-annual variation. The exceptions were predominantly schooling taxa (e.g. Siganidae and Lutjanidae) or relatively rare, such that a few more fishes in 1 year would add a high propor- 
tion of variation (e.g. Dascyllus, Serranidae). A notable exception to these generalisations was Chrysiptera spp., which showed high inter-annual variation that arose from several years and regions in which numbers increased markedly in one year (presumably as a result of a recruitment pulse) before dropping to previous levels in the subsequent year. Whilst we consider these spikes as real changes in the population, at least locally, the variance they introduce to the model is not adequately accounted for by the linear or quadratic terms which are designed to account for real changes in population over longer periods. The observed fluctuations may reflect any of a number of ecological processes, including relocation as a result of ontogenetic shifts in habitat preference or density-dependent interactions, high mortality rates of abundant early-year classes or even short life expectancies, so that the variation was in fact not an error, but rather a real change in the population. It is interesting to note that additional data from the AIMS LTMP not included in these analyses show similar single-year spikes in abundance for several species of the genus Pomacentrus (AIMS LTMP unpubl. data).

Our study has shown that most of the considerable variation in abundance estimates from visual surveys of belt transects is manifest at short time scales, and obviously does not represent real net fluctuations in population size. It is highly likely that this variation stems from the mobility of the fishes over short periods, and possibly over short distances. What we have not resolved is whether such movements are largely the result of essentially random movements or are being dictated by some more deterministic process such as tidal cycle. Irrespective of the nature of the processes causing the observed variation, the sampling error arising from it must be included in the interpretation of any longer term, and perhaps spatial, comparison of abundance estimates. Accordingly, we suggest that comparisons of abundances of mobile organisms between spatial entities sampled at different times should include consideration of the temporal variation likely to be associated with each estimate. Since much of this variation may stem from the mobility of fish beyond the bounds of the sampling units, it might be argued that sampling units should be selected that encompass the 'home ranges' of the principal target species. In many cases, however, this will be logistically impossible, and likely to incur higher sampling bias and poorer cost-efficiency than simply increasing spatial replication. Perhaps a more appropriate approach would be to undertake a temporally replicated pilot study over several days in each of a few consecutive months to ensure that estimates of selected target species are repeatable within bounds acceptable to the study in question. Estimates of uncer- tainty in counts derived from such short-term sampling should then be used to qualify any differences observed among counts taken over longer periods.

Acknowledgements. We thank Andrew Halford, Alistair Cheal and others in the Australian Institute of Marine Science Long Term Monitoring Team for field support. B.D.M was supported by the Great Barrier Reef Marine Park Authority and the Cooperative Research Centre for the Ecologically Sustainable Development of the Great Barrier Reef. This article is Australian Institute of Marine Science contribution number 1034.

\section{LITERATURE CITED}

Andrew NL, Mapstone BD (1987) Sampling and the description of spatial pattern in marine ecology. Oceanogr Mar Biol Annu Rev 25:39-90

Ault TR, Johnson CR (1998) Spatially and temporally predictable fish communities on coral reefs. Ecol Monogr 68: $25-50$

Bohnsack JA (1983) Species turnover and the order verses chaos controversy concerning reef fish community structure. Coral Reefs 1:223-228

Bray RN (1981) Influence of water currents and zooplankton densities on daily foraging movements of blacksmith, Chromis punctipinnis, a planktivorous reef fish. Fish Bull (Wash DC) 78:829-841

Brock RE, Lewis C, Wass RC (1979) Stability and structure of a fish community on a coral patch reef in Hawaii. Mar Biol 45:281-292

Brock VE (1954) A preliminary report on a method for assessing reef fish populations. J Wildl Manag 18:297-308.

Buckley RM, Hueckel GJ (1989) Analysis of visual transects for fish assessment on artificial reefs. Bull Mar Sci 44:893-898

Cheal AJ, Thompson AA (1997) Comparing visual counts of coral reef fish: implications of transect width and species selection. Mar Ecol Prog Ser 158:241-248

Crowder MJ, Hand DJ (1990) Analysis of repeated measures, Chapman \& Hall, New York

Fautin DG, Allen GR (1992) Field guide to anemonefishes and their host sea anemones. Western Australian Museum, Perth

Fowler AJ (1987) The development of sampling strategies for population studies of coral reef fishes. A case study. Coral Reefs 6:49-58

Galzin R (1987) Structure of fish communities of French Polynesian coral reefs. II. Temporal scales. Mar Ecol Prog Ser 41:137-145

Gladfelter WB (1979) Twilight migrations and foraging activities of the copper sweeper Pempheris schombuegki (Teleostei: Pempheridae). Mar Biol 50:109-119

Gladfelter WB, Gladfelter EH (1978) Fish community structure as a function of habitat structure on West Indian patch reefs. Rev Biol Trop 26:65-84

Green RH (1979) Sampling design and statistical methods for environmental biologists. Wiley Interscience, New York

Helfman GS (1986) Fish behaviour by day, night and twilight. In: Pitcher TJ (ed) The behaviour of teleost fishes, 1st edn. Johns Hopkins University Press, Baltimore, MD, p 366-387

Hodgson G (1999) A global assessment of human effects on coral reefs. Mar Pollut Bull 38(5):345-355

Klump DW, Polunin NVC (1990) Algal production, grazes and habitat partitioning on a coral reef: positive correlation 
between grazing rate and food availability. In: Barnes M et al. (eds) Proc 24th Eur Mar Biol Symp. University of Aberdeen Press, Aberdeen, p 372-388

Kulbicki M (1998) How the acquired behaviour of commercial reef fishes may influence the results obtained from visual census. J Exp Mar Biol Ecol 222:11-30

Lewis AR (1997) Recruitment and post-recruit immigration affect the local population size of coral reef fishes. Coral Reefs 16:139-149

Mapstone BD, Ayling AM (1998) An investigation of optimum methods and unit sizes for the visual estimation of abundances of some coral reef organisms. Great Barrier Reef Marine Park Authority Res Pub Ser. 47, Townsville, Queensland

McCormick MI, Choat JH (1987) Estimating total abundance of a large temperate-reef fish using visual strip-transects. Mar Biol 96:469-478

Ogden JC, Buckman NS (1972) Movements, foraging groups, and diurnal migrations of the stripped parrotfish Scarus croicensis Bloch (Scaridae). Ecology 54:589-596

Ogden JC, Ebersole JP (1981) Scale and community structure of coral reef fishes: a long-term study of a large artificial reef. Mar Ecol Prog Ser 4:97-103.

Polunin NVC, Klump DW (1989) Ecological correlates of foraging periodicity in herbivorous reef fishes of the Coral Sea. J Exp Mar Biol Ecol 126:1-20

Sale PF (ed) (1991) The ecology of fishes on coral reefs. Academic Press, San Diego, CA

Sale PF, Douglas WA (1981) Precision and accuracy of visual census techniques for fish assemblages on coral patch reefs. Environ Biol Fish 5:243-249

Sale PF, Douglas WA (1984) Temporal variability in the community structure of fish on coral patch reefs. Ecology 65: 409-422

Sale PF, Sharp BJ (1983) Correction for bias in visual transect censuses of coral reef fishes. Coral Reefs 2:37-42

Sale PF, Steel WJ (1989) Temporal variability in patterns of association among fish species on coral patch reefs. Mar Ecol Prog Ser 51:35-47

Samoilys MA (1997) Periodicity of spawning aggregations of coral trout Plectropomus leopardus (Pisces: Serranidae) on

Editorial responsibility: Tony Underwood (Contributing

Editor), Sydney, Australia the northern Great Barrier Reef. Mar Ecol Prog Ser 160 149-159

Samoilys MA, Squire L (1994) Preliminary observations on the spawning behaviour of coral trout, Plectropomus leopardus (Pisces: Serranidae), on the Great Barrier Reef. Bull. Mar Sci 54:332-342

SAS Institute (1997) SAS/Stat Software: changes and enhancement through release 6.12, Cary, NC

Smith CL, Tyler JC (1975) Succession and stability in fish communities of the dome-shaped patch reefs in the West Indies. Am Mus Novit 2572:1-18

Stewart-Oaten A (1996) Problems in the analysis of environmental monitoring data. In: Schmitt RJ, Osenberg CW (eds) Detection of ecological impacts: conceptual issues and application in coastal marine habitats. Academic Press, San Diego, CA, p 109-132

Thompson AA, Mapstone BD (1997) Observer effects and training in underwater visual surveys of reef fishes. Mar Ecol Prog Ser 154:53-63

Underwood AJ (1991) Beyond BACI: experimental designs for detecting human environmental impacts on temporal variations in natural populations. Aust J Mar Freshw Res 42: $569-587$

Underwood AJ (1993) The mechanics of spatially replicated sampling programs to detect environmental impacts in a variable world. Aust J Ecol 18:99-118

Underwood AJ (1997) Experiments in ecology: their logical design and interpretation using analysis of variance. Cambridge University Press, Cambridge

Watson RA, Carlos GM, Samoilys MA (1995) Bias introduced by the non-random movement of fish in visual transect surveys. Ecol Model 77:205-214

Winer BJ, Brown DR, Michels KM (1992) Statistical Principles in experimental design, 3rd edn. McGraw-Hill, Kogakusha

Zeller DC (1997) Home range and activity patterns of the coral trout Plectropomus leopardus (Serranidae). Mar Ecol Prog Ser 154:65-77

Zeller DC (1998) Spawning aggregations: patterns of movement of the coral trout Plectropomus leopardus (Serranidae) as determined by ultrasonic telemetry. Mar Ecol Prog Ser 162:253-263

Submitted: October 19, 2000; Accepted: November 20, 2001 Proofs received from author(s): April 10, 2002 